\section{Urologia}

Internationalis

\section{Stefan Zastrow \\ Oliver W. Hakenberg Manfred P. Wirth}

Department of Urology,

University Hospital 'Carl Gustav Carus', Technical University of Dresden,

Dresden, Germany

\title{
Significance of Testicular Microlithiasis
}

\section{Abstract}

Introduction: Testicular microlithiasis is an uncommon condition characterized by calcifications within the seminiferous tubules. The true prevalence in a normal population has not been defined. Methods: A review of the literature with emphasis on the connection between testicular microlithiasis and testicular malignancy was carried out. Results: Testicular microlithiasis is associated with different testicular pathologies, including testicular cancer. However, a direct causative connection between testicular microlithiasis and testicular pathologies is not supported by the literature. Conclusions: $\mathrm{Pa}$ tients with testicular microlithiasis should be followed up regularly. Further investigations concerning the etiology of testicular microlithiasis remain to be done.

Copyright (C) 2005 S. Karger AG, Basel

\section{Introduction}

Testicular microlithiasis is a condition characterized by multiple calcifications distributed randomly throughout the testicular parenchyma (fig. 1). It was first described radiologically by Priebe and Garret [1] in 1970. The appearance on ultrasound is typical with scattered multiple echogenic lesions distributed over the testis. The pattern of distribution is usually diffuse in both testes, but other patterns (unilateral or focal in one testis) have been described as well. The condition is important because of its possible association with testicular malignancies. The true prevalence of testicular microlithiasis in otherwise healthy individuals remains unclear, because most studies have been done in patients who presented with scrotal symptoms. The aim of this article is to review the current knowledge about this entity.

\section{Morphology}

Morphologically, the microliths consist of degenerated intratubular cells which form a calcified core. This core is surrounded by a series of concentric layers. The outer

Fig. 1. Testicular microlithiasis in a 23 year old male presenting with scrotal pain.

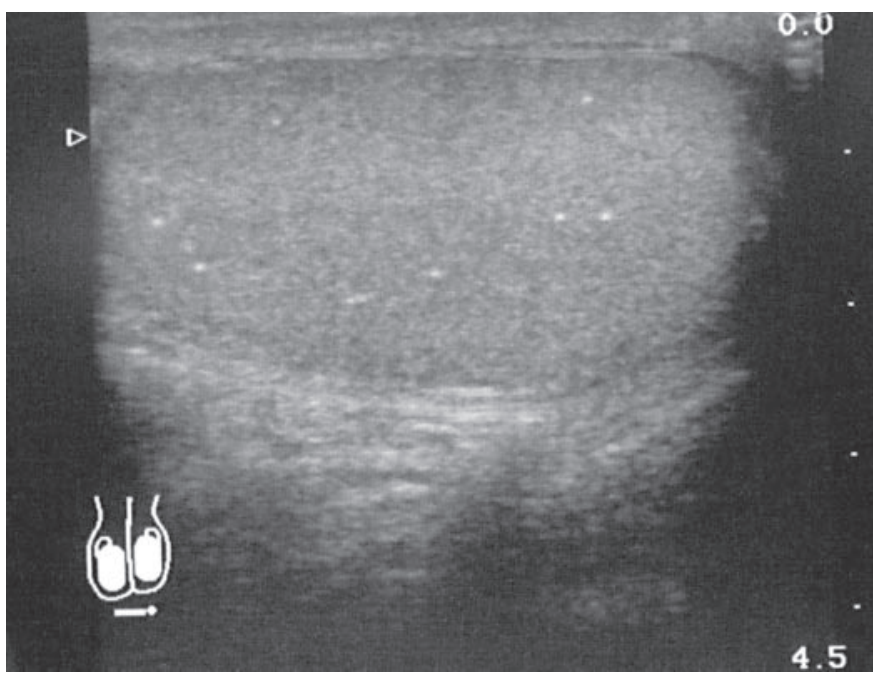

\section{KARGER}

Fax +41613061234 E-Mail karger@karger.ch www.karger.com
Dr. Stefan Zastrow

Department of Urology, University Hospital 'Carl Gustav Carus', Technical University Fetscherstrasse 74, DE-01307 Dresden (Germany)

Tel. +49 351458 2447, Fax +49 3514584333

E-Mail Stefan.Zastrow@uniklinikum-dresden.de 
layer consists of cystoplasmic debris with vesicles, degenerated mitochondria, and collagen fibers. The intermediate layer contains bundles of collagen fibers. The innermost layer consists of multiple lamellae [2]. A meticulous morphological description of the development of testicular microliths, however, has not been done, thus leaving unexplained the origin and the exact mechanism by which these calcifications develop.

In a histopathological classification two different forms of testicular microlithiasis have been described by Renshaw [3]. The most frequent type is represented by laminated calcifications. They were found in 38 (29\%) of 131 pathological specimens. Laminated calcifications occurred in association with testicular malignancies (pure seminomas, embryonal carcinomas, and mixed germ cell tumors), in cryptorchid testes, and also in normal testes. The second type consists of hematoxylin bodies. These hematoxylin bodies are exceptionally encountered in connection with testicular malignancies like pure embryonal carcinomas and mixed tumors (embryonal carcinoma with yolk sac tumor and embryonal carcinoma with seminoma, respectively, in 2 cases). Of 131 pathological specimens, only $6(5 \%)$ contained hematoxylin bodies.

\section{Testicular Microlithiasis and Associated Conditions}

Testicular microlithiasis can occur in connection with numerous testicular pathologies but also in otherwise normal testes. Pathological conditions include malignancies, cryptorchism [4], varicocele [5-7], testicular torsion [8], infertility $[6,7,9,10]$, epididymo-orchitis [5], Klinefelter syndrome [11], male pseudohermaphroditism [8], neurofibromatosis, and HIV infection [12].

\section{Testicular Malignancies}

The connection between testicular microlithiasis and testicular malignancies (seminoma, teratoma, mixed tumors, and carcinoma in situ) has been frequently described. In a radiographic study performed on testicular cancer orchiectomy specimens, Ikinger at al. [13] identified microcalcifications in $74 \%$ of their cases. In benign conditions, microcalcifications could be found in only $16 \%$ of the cases. Thus in testicular cancer specimens a higher incidence of testicular microlithiasis is present.

Although testicular microlithiasis often can be seen together with testicular tumors, only a few case reports [5,
14-22] have been published describing the development of testicular cancers in patients after the diagnosis of testicular microlithiasis (see table 1). So it remains unclear whether testicular microlithiasis has to be considered a premalignant condition or represents a precursor state to testicular malignancy.

A prognostic value of testicular microlithiasis concerning the development of testicular cancer cannot be derived from the published data, with one exception, however: if testicular microlithiasis occurs in the remaining testis after orchiectomy for testicular malignancies, it seems to be connected with a higher risk of developing a secondary malignancy in this testis [23]. Furthermore, if testicular microlithiasis can be found in the contralateral testis after orchiectomy because of malignancies, the risk of carcinoma in situ is increased which has been demonstrated by Holm et al. [24] in a retrospective study of 64 patients.

Derogee et al. [14] provided evidence for testicular microlithiasis as a premalignant condition. These authors retrospectively reviewed 1,535 patients who underwent ultrasound examination of the external genitalia during a period of 6 years. The indications for ultrasound included spermatocele, epididymitis, hydrocele, or suspected malignoma. They found microliths in $63(4.1 \%)$ of these 1,535 patients. A preferred side could not be detected ( 28 left, 25 right, 10 bilateral). $46 \%$ of the patients with testicular microlithiasis had a concomitant tumor in the same testis. A strong correlation between testicular microlithiasis and testicular tumor was calculated in this series. A preferred tumor type could not be found. Histological examinations were performed in 28 cases. Testicular microlithiasis was seen exclusively inside the testicular tumor in only 4 cases. In most cases testicular microlithiasis showed a preference for a location outside the testicular tumor. Patients with testicular microlithiasis but no tumor were followed up. During the follow-up period (median 61.8 months) 1 of 31 patients developed a combined teratoma and seminoma 35 months after the diagnosis of testicular microlithiasis. According to the authors [14], regular follow-up of patients with testicular microlithiasis is warranted. Testicular biopsy should be considered an option in these patients.

According to the findings of another retrospective study [25], the clinical significance of testicular microlithiasis remains unclear. In this study 1,710 ultrasound examinations of adults were reviewed. Testicular microlithiasis was found in 11 cases $(0.6 \%)$. In all cases it was bilateral. In 5 cases it was associated with a testicular tumor (3 seminomas, 1 teratoma, and 1 combined semi- 
Table 1. Selected case histories

\begin{tabular}{|c|c|c|c|c|c|}
\hline $\begin{array}{l}\text { Case } \\
\text { No. }\end{array}$ & $\begin{array}{l}\text { Age } \\
\text { years }\end{array}$ & History & Tumor type & $\begin{array}{l}\text { Time to tumor } \\
\text { appearance after } \\
\text { diagnosis of TM }\end{array}$ & $\begin{array}{l}\text { Reference } \\
\text { No. }\end{array}$ \\
\hline 1 & 32 & infertility, TM on the right side & embryonal carcinoma & 10 months & 16 \\
\hline 2 & 17 & asymptomatic TM & yolk sac tumor & 4 years & 17 \\
\hline 3 & 21 & initially pain, hemospermia, unilateral TM & mixed germ cell tumor & 3 years & 18 \\
\hline 5 & 40 & seminoma 11 years before, TM bilaterally & seminoma & 11 years & 15 \\
\hline 6 & 47 & testicular pain, bilateral TM & seminoma, carcinoma in situ & 6 months & 20 \\
\hline 7 & n.i. & $\begin{array}{l}\text { left embryonal carcinoma treated with } \\
\text { orchiectomy and chemotherapy } 10 \text { years ago, } \\
\text { cryptorchid testes in childhood on both sides }\end{array}$ & combined teratoma/seminoma & 35 months & 14 \\
\hline 10 & n.i. & infertility, bilateral TM & seminoma & 5 years & 21 \\
\hline 11 & n.i. & control group, volunteer, right TM & right seminoma & 3 years & 21 \\
\hline 12 & n.i. & retractile left testis, left $\mathrm{TM}$ & left seminoma & 12 months & 22 \\
\hline
\end{tabular}

$\mathrm{TM}=$ Testicular microlithiasis; n.i. = not indicated.

noma/teratoma). Other concomitant pathologies were hypogonadism/oligospermia, varicocele, and cysts of spermatic cord or epididymis. During a mean follow-up period of 15.9 (range 2-49) months, no testicular tumor developed in testes with microlithiasis. The authors underlined the importance of a complete diagnostic workup to rule out testicular malignancies in patients who have been diagnosed as having testicular microlithiasis. Unfortunately, the authors do not indicate the reasons for testicular ultrasound examination in their cohort, thus leaving unanswered the question if their figures can be interpreted as representing the incidence of testicular microlithiasis in an otherwise asymptomatic cohort.

According to Otite et al. [5] there is no sufficient evidence for classifying testicular microlithiasis as a premalignant condition. They retrospectively analyzed 3,026 patients who underwent testicular ultrasound examination because of testicular symptoms (pain, swelling, infertility) over a period of 5 years. They found testicular microlithiasis in 54 patients (1.77\%). It was bilateral in 39 of 54 patients. Eighty-two of all patients had testicular tumors, but only $16(19.5 \%)$ of these tumor patients had testicular microlithiasis. Malignancies connected with testicular microlithiasis included 6 seminomas, 4 teratomas, 5 mixed tumors, and 1 embryonal carcinoma. Other testicular pathologies occurring with testicular microlithiasis were hydroceles/epididymal cysts $(n=14)$, varicoceles $(n=7)$, epididymitis $(n=2)$, and small testes $(\mathrm{n}=8)$. It is worth mentioning that also 14 testes with testicular microlithiasis showed otherwise normal findings. Only 2 patients developed testicular cancer during the follow-up period ( 1 seminoma after 2 years and 1 seminoma with a small embryonal component 4 years after curative therapy of a metastatic embryonal carcinoma).

Ganem et al. [12] reported their experience with 22 patients found to have testicular microlithiasis over a 4year period. They also could not find sufficient evidence for classifying testicular microlithiasis as either a premalignant condition or a causative agent for testicular neoplasia. Their patients were drawn from approximately 1,100 testicular ultrasound investigations. 16 of the 22 patients had bilateral testicular microlithiasis. A coincidence with malignancies occurred in 8 patients $(36 \%)$. The types of malignancies included 6 stage 1 seminomas, 1 mixed nonseminomatous germ cell tumor, and 1 meta- 
static yolk sac tumor. During the follow-up period (mean 32 , range 1-96 months), no patient with testicular microlithiasis who did not have testicular cancer at the time of presentation subsequently developed a testicular malignancy. Of the patients who underwent ultrasound investigation because of infertility, 5 out of the 22 patients $(23 \%)$ had testicular microlithiasis as well. 3 of the 22 patients (14\%) with spermatic cord torsion had testicular microlithiasis. The authors also reported for the first time the finding of testicular microlithiasis in patients with neurofibromatosis $(\mathrm{n}=1)$ and AIDS $(\mathrm{n}=1)$. However, as there is no obvious relationship between AIDS, neurofibromatosis, and testicular microlithiasis; these findings were probably coincidental. Concerning the connection between testicular neoplasia and testicular microlithiasis, the attractive hypothesis is presented that testicular microlithiasis could be the manifestation of another undefined pathology which predisposes to malignant (and possibly benign, e.g., infertility) disease. The authors recommend regular follow-up with testicular ultrasound examinations.

However, strong evidence against a connection between testicular microlithiasis and testicular cancer has been presented by Peterson at al. [26]. These authors performed a prospective screening study in 1,504 healthy young men between 18 and 35 years of age. In this population, 84 subjects $(5.6 \%)$ had testicular microlithiasis. It occurred bilaterally in $66.7 \%$ of all cases. The incidence of testicular microlithiasis in this study was far higher than the incidence of testicular cancer which according to the authors is a strong argument against the epidemiological association of malignancy and testicular microlithiasis. They also found a higher proportion of testicular microlithiasis in black men (14.4\%) who, on the other hand, have a very low incidence of testicular cancer. In addition, the incidence of testicular microlithiasis was higher in men from the southeast of the USA, a region which has the lowest incidence of testicular cancer. These observations do not support a connection between testicular cancer and microlithiasis. The authors, therefore, question the necessity of a regular and cost-intensive follow-up of testicular microlithiasis patients and suggest regular self-examinations. It must be underlined that these results were found in a clearly asymptomatic and otherwise healthy population. This increases the value of this study, because selection of patients with testicular symptoms has been omitted.

Similarly, Middleton et al. [27] were not able to provide clear evidence for testicular microlithiasis as a premalignant condition. They recorded data of 1,079 pa- tients referred for scrotal ultrasound. The overall prevalence of testicular microlithiasis in this group was $18.1 \%$. The authors divided testicular microlithiasis into classic testicular microlithiasis with $\geq 5$ microliths in one ultrasound picture and limited testicular microlithiasis with $<5$ microliths. The prevalences were 3.7 and $14.4 \%$ for classic and limited testicular microlithiasis, respectively. Tumors occurred in $8 \%$ of the patients with classic and in $5.8 \%$ of those with limited testicular microlithiasis (difference not significant). In this study, $>90 \%$ of the patients with testicular microlithiasis had no tumor.

After reviewing the data presented, it must be conluded that a classification of testicular microlithiasis as a premalignant condition cannot be clearly supported. However, to some degree it occurs with testicular malignancies. The coincidence of testicular cancer and testicular microlithiasis suggests that both conditions might share a common etiology.

\section{Testicular Microlithiasis and Infertility}

In a retrospective analysis performed by Thomas et al. [6], a coincidence of testicular microlithiasis ( $>5$ echogenic foci/ picture) and infertility was found in 5 out of 159 infertile men (3.1\%) having undergone testicular ultrasound examination. All of these 5 men also had other testicular pathologies ( 3 had varicoceles, 1 had a history of testicular torsion, and 1 had a missing contralateral testis). Concerning varicoceles, it is important to note that 59 of the 159 patients in this study had this condition. Thus, only $8.5 \%$ of all patients with a varicocele had testicular microlithiasis. There were also 5 additional men with minimal microlithiasis ( $<5$ echogenic foci/picture). When these patients were compared with men with generalized testicular microlithiasis ( $>5$ echogenic foci/picture), they showed a significantly better sperm migration test and sperm motility. There were no significant differences between the groups with respect to sperm count or number of white cells. But the data suggested a relationship between degree of calcifications and sperm function.

Aizenstein et al. [9] reviewed 180 infertile men and found 5 patients $(2.8 \%)$ with testicular microlithiasis. Sasagawa et al. [10] found 1 case among 125 testicular biopsies performed because of infertility. Kessaris and Mellinger [7] detected 2 patients (1.3\%) out of 150 infertile men. The 1 st patient had a left-side grade I varicocele. The 2 nd patient had bilateral varicoceles (right grade I, left grade II) and a history of herniorrhaphy as a child. 
Four months after bilateral microsurgical correction of the varicoceles and right scrotal exploration, this patient's wife became pregnant.

\section{Management of Patients with Testicular Microlithiasis}

Presently, regular self-examinations are recommended in patients with testicular microlithiasis. The roles of ultrasound controls every $6-12$ months and regular investigation of tumor markers recommended in some studies remain unclear. There is no scientific basis for a biopsy in isolated testicular microlithiasis without further accompanying pathologies. A biopsy may be warranted in case of additional pathological ultrasound or clinical findings, in focal or unilateral testicular microlithiasis, or in cases of contralateral tumor or infertility with cryptorchism or atrophic testes $[28,29]$.

\section{Conclusions}

Testicular microlithiasis is not a rare condition. However, it is an incidental finding on scrotal ultrasound examination because of other testicular conditions. Although it can occur synchronously with testicular malignancies in a more than random fashion, a causality between testicular microlithiasis and testicular cancer is not supported by the literature. However, once diagnosed, it requires regular follow-up, at least by self-examination. Further studies to elucidate the etiological basis and significance of this condition remain to be done.

\section{References}

1 Priebe CJ Jr, Garret R: Testicular calcification in a 4-year-old boy. Pediatrics 1970;46:785788.

2 Vegni-Talluri M, Bigliardi E, Vanni MG, Tota G: Testicular microliths: Their origin and structure. J Urol 1980;124:105-107.

3 Renshaw AA: Testicular calcifications: Incidence, histology and proposed pathological criteria for testicular microlithiasis. J Urol 1998; 160:1625-1628.

4 Nistal M, Paniagua R, Diez-Pardo JA: Testicular microlithiasis in 2 children with bilateral cryptorchidism. J Urol 1979;121:535-537.

5 Otite U, Webb JA, Oliver RT, Badenoch DF, Nargund VH: Testicular microlithiasis: Is it a benign condition with malignant potential? Eur Urol 2001;40:538-542.

6 Thomas K, Wood SJ, Thompson AJ, Pilling D, Lewis-Jones DI: The incidence and significance of testicular microlithiasis in a subfertile population. Br J Radiol 2000;73:494-497.

7 Kessaris DN, Mellinger BC: Incidence and implication of testicular microlithiasis detected by scrotal duplex sonography in a select group of infertile men. J Urol 1994;152(5 Pt 1):1560 1561.

8 Jaramillo D, Perez-Atayde A, Teele RL: Sonography of testicular microlithiasis. Urol Radiol 1989;11:55-57.

9 Aizenstein RI, DiDomenico D, Wilbur AC, O’Neil HK: Testicular microlithiasis: Association with male infertility. J Clin Ultrasound 1998;26:195-198.

10 Sasagawa I, Nakada T, Kazama T, Satomi S, Katayama T, Matuda S: Testicular microlithiasis in male infertility. Urol Int 1988;43:368369.
11 Aizenstein RI, Hibbeln JF, Sagireddy B, Wilbur AC, O'Neil HK: Klinefelter's syndrome associated with testicular microlithiasis and mediastinal germ cell neoplasm. J Clin Ultrasound 1997;25:508-510.

12 Ganem JP, Workman KR, Shaban SF: Testicular microlithiasis is associated with testicular pathology. Urology 1999;53:209-213.

13 Ikinger U, Wurster K, Terwey B, Mohring K: Microcalcifications in testicular malignancy: Diagnostic tool in occult tumor? Urology 1982; 19:525-528.

14 Derogee M, Bevers RF, Prins HJ, Jonges TG, Elbers FH, Boon TA: Testicular microlithiasis, a premalignant condition: Prevalence, histopathologic findings, and relation to testicular tumor. Urology 2001;57:1133-1137.

15 Gooding GA: Detection of testicular microlithiasis by sonography. AJR Am J Roentgenol 1997; 168:281-282.

16 Salisz JA, Goldman KA: Testicular calcifications and neoplasia in patient treated for subfertility. Urology 1990;36:557-560.

17 McEniff N, Doherty F, Katz J, Schrager CA, Klauber G: Yolk sac tumor of the testis discovered on a routine annual sonogram in a boy with testicular microlithiasis. AJR Am J Roentgenol 1995; 164:971-972.

18 Winter TC 3rd, Zunkel DE, Mack LA: Testicular carcinoma in a patient with previously demonstrated testicular microlithiasis. J Urol 1996;155:648.

19 Frush DP, Kliewer MA, Madden JF: Testicular microlithiasis and subsequent development of metastatic germ cell tumor. AJR Am J Roentgenol 1996;167:889-890.

20 Golash A, Parker J, Ennis O, Jenkins BJ: The interval of development of testicular carcinoma in a patient with previously demonstrated testicular microlithiasis. J Urol 2000;163: 239.
21 von Eckardstein S, Tsakmakidis G, Kamischke A, Rolf C, Nieschlag E: Sonographic testicular microlithiasis as an indicator of premalignant conditions in normal and infertile men. J Androl 2001;22:818-824.

22 Cornford PA, Baird AD, Woolfenden KA: Testicular microlithiasis needs long-term surveillance. Scand J Urol Nephrol 2001;35:243244

23 Bach AM, Hann LE, Shi W, Giess CS, Yoo $\mathrm{HH}$, Sheinfeld J, Thaler HT: Is there an increased incidence of contralateral testicular cancer in patients with intratesticular microlithiasis? AJR Am J Roentgenol 2003; 180:497500 .

24 Holm M, Hoei-Hansen CE, Rajpert-De Meyts E, Skakkebaek NE: Increased risk of carcinoma in situ in patients with testicular germ cell cancer with ultrasonic microlithiasis in the contralateral testicle. J Urol 2003; 170(4 Pt 1):1163-1167.

25 Hobarth K, Susani M, Szabo N, Kratzik C: Incidence of testicular microlithiasis. Urology 1992;40:464-467.

26 Peterson AC, Bauman JM, Light DE, McMann LP, Costabile RA: The prevalence of testicular microlithiasis in an asymptomatic population of men 18 to 35 years old. J Urol 2001;166: 2061-2064.

27 Middleton WD, Teefey SA, Santillan CS: Testicular microlithiasis: Prospective analysis of prevalence and associated tumor. Radiology 2002;224:425-428.

28 Kim B, Winter TC 3rd, Ryu JA: Testicular microlithiasis: Clinical significance and review of the literature. Eur Radiol 2003;13:25672576.

29 Ganem JP: Testicular microlithiasis. Curr Opin Urol 2000;10:99-103. 